\title{
Prognostic significance of successful ablation with radioiodine of differentiated thyroid cancer patients
}

\author{
Frederik A Verburg ${ }^{1}$, Bart de Keizer ${ }^{1}$, Cornelis J M Lips ${ }^{2}$, Pierre M J Zelissen ${ }^{2}$ and John M H de Klerk ${ }^{1}$ \\ Departments of Nuclear Medicine ${ }^{1}$ and Endocrinology ${ }^{2}$, University Medical Center Utrecht, Heidelberglaan 100, 3584 CX Utrecht, The Netherlands
}

(Correspondence should be addressed to F A Verburg, Burg. Allardstraat 254931 CA Geertruidenberg, The Netherlands; Email: e.verburg@azu.nl)

\begin{abstract}
Objectives: Currently, little is known about the prognostic significance of achieving successful ablation with the first dosage of I-131 in patients with differentiated thyroid cancer. This study aimed to assess the following: (i) whether successful or unsuccessful ablation at post-ablation follow-up has prognostic consequences; (ii) possible factors predicting success of ablation in a patient.

Methods: In order to do this, we retrospectively studied 180 patients with a median follow-up of 55 months. Ablation was considered to be successful if 1 year after the initial dosage of I-131 patients fulfilled all of the following criteria: not dead from thyroid cancer, no additional therapy needed for any kind for thyroid cancer within the first year, undetectable thyroglobulin (Tg) levels under TSH stimulation, and negative I-131 scintigraphy. Tg levels at the time of ablation $(P<0.001)$, lymph node metastasis $(P=0.04)$ and distant metastasis $(P<0.001)$ have a significant influence on the success of ablation. $P$ values were calculated by Mann-Whitney U test and Chi-square test, respectively. Results: Patients with successful ablation had a better prognosis than those with unsuccessful ablation: disease-free survival was $87 \%$ versus $49 \%$ after 10 years; additionally, thyroid-cancer related survival was $93 \%$ versus $78 \%$.

Conclusion: We conclude that the extent of the remaining normal or neoplastic thyroid tissue influences the outcome of ablation, and that successful ablation leads to a better prognosis. It seems that it is very important to achieve complete ablation as soon as possible in order to ensure the best possible prognosis for a patient.

European Journal of Endocrinology 152 33-37
\end{abstract}

\section{Introduction}

Treatment of differentiated (papillary or follicular) thyroid cancer consists of thyroidectomy and an ablative dosage of iodine-131 (1). The addition of I-131 ablation, after surgery, leads to a significantly improved prognosis, especially in patients who are at high risk of recurrence of or death by thyroid cancer (2-6). Unfortunately, the first dosage of I-131 is not always sufficient to achieve complete ablation of thyroid remnants $(7-13)$.

This study aimed to assess the following: (i) whether successful or unsuccessful ablation at post-ablation follow-up has prognostic consequences; (ii) possible factors predicting success of ablation in a patient.

\section{Patients, materials and methods}

\section{Patients}

All patients with differentiated thyroid carcinoma referred to our centre for their first, ablative dosage of I-131 after 1 January 1990 were reviewed retrospectively.
To be included in this study, at least one of the following criteria had to apply:

- The patient returned for diagnostic scintigraphy and measurement of thyroglobulin $(\mathrm{Tg})$ levels during thyroid-stimulating hormone (TSH) administration (Tg off) 1 year after ablation.

- The patient had received an additional therapeutic dosage of I-131 within the first year following the ablative dosage of I-131.

- The patient died of thyroid cancer within the first year following the ablative dosage of I-131.

Out of 192 eligible patients, 180 met at least one of these criteria. The patient characteristics are given in Table 1.

\section{Initial treatment}

All patients underwent (near) total thyroidectomy, and received an ablative dosage of I-131 4-6 weeks after thyroidectomy. Between surgery and ablation, patients did not receive levothyroxine (LT4) supplementation, and they were instructed to have a low-iodine diet for 
Table 1 Patient characteristics.

\begin{tabular}{lc}
\hline$n$ & 180 \\
Mean age in years (range) & $46(14-84)$ \\
Female/male & $126 / 54$ \\
Papillary/follicular & $123 / 57$ \\
\hline
\end{tabular}

1 week ( 5 days before and 2 days after I- 131 administration) (14).

To prevent 'stunning' of thyroid remnants (15-17), no diagnostic scintigraphy was performed before the administration of the ablative dosage of I-131. Patients were treated according to a fixed dosage protocol: $3700 \mathrm{MBq}$ of I-131 in cases without known lymphnode or distant metastasis, $5550 \mathrm{MBq}$ of $\mathrm{I}-131$ in cases of pre- or perioperatively detected nodular involvement, or $7400 \mathrm{MBq}$ of $\mathrm{I}-131$ in cases of known distant metastasis.

\section{Follow-up after ablation}

In our department, patients that are treated for differentiated thyroid carcinoma are usually evaluated by the measuring of $\mathrm{Tg}$ levels and whole-body scintigraphy using $370 \mathrm{MBq}$ I-131 1 year after administration of the ablative dosage, which happens after LT4 withdrawal for 4 weeks. In all but four patients, this resulted in TSH levels of $>30 \mathrm{mU} / \mathrm{l}$, with a maximum of $469 \mathrm{mU} / \mathrm{l}$.

Ablation was considered to be successful if, 1 year after the initial dosage of I-131, patients fulfilled all of the following criteria:

- not dead from thyroid cancer

- no additional therapy needed for any kind for thyroid cancer within the first year

- undetectable Tg levels under TSH stimulation

- negative I-131 scintigraphy.

$\mathrm{Tg}$ levels were not used as a criterion for success of ablation in the cases when a patient tested positive for the presence of $\mathrm{Tg}$ antibodies, since test results for $\mathrm{Tg}$ cannot be considered reliable in these patients $(18,19)$.

\section{Disease-free interval, recurrence and survival}

A disease-free patient was considered to have a recurrence if one or more of the following conditions developed:

- detectable Tg levels

- pathological evidence of disease, as by fine-needle aspiration biopsy

- positive I-131 scintigraphy.

In our analysis, the disease-free interval started at the time of the first completely negative follow-up. This could be at the time of the 1-year post-ablation scintigram (as in the group with successful ablation), or at a later follow-up scintigram if a patient required additional treatment to become free of disease (as in the group with unsuccessful ablation). Disease-free survival was considered to end at the moment of detection of a sign of recurrence. Thyroid-cancer specific survival was considered to start at the moment of administration of the ablative dosage of radioiodine.

\section{Statistical analysis}

For statistical analysis, we used SPSS Version 10.1 for Windows (SPSS Inc., Chicago, IL, USA). Statistical significance was shown with $P<0.05$. For testing between different groups of patients, the Mann-Whitney test ( $\mathrm{Z}$ approximation) was used if one of the variables involved was continuous. The chi-square test was used if both variables involved were categorical data. Survival times were analysed by the method of Kaplan-Meier. Additionally, the difference between survival curves was examined by the log rank test.

\section{Results}

\section{Success of ablation}

According to the criteria used in this study, ablation was successful in 110 out of 180 patients (61\%) (Fig. 1). Median follow-up time was 55 months. Twelve patients died of thyroid cancer, of which four had died within 1 year of initial treatment. Sixteen patients had recurrence of thyroid cancer. Twenty-nine patients never became free of the disease during follow-up, including six out of the eight patients who died. Seven of those 29 patients

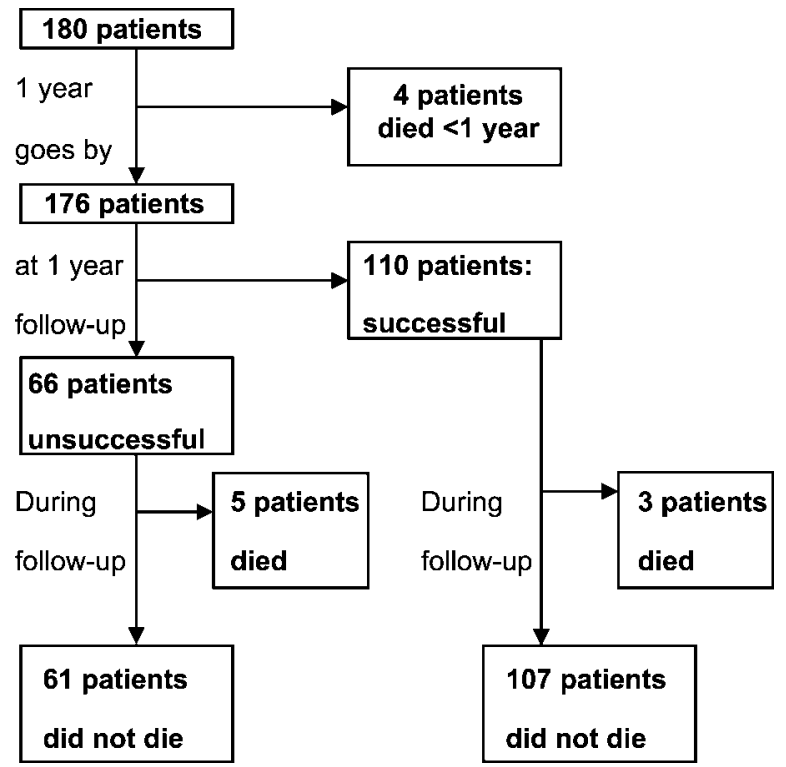

Figure 1 Status of patients, 1 year after administration of the ablative dosage of I-131. die: to die of differentiated thyroid carcinoma before the end of follow-up. 
had a short follow-up of less than 4 years, so they may not have received the maximum treatment yet. Two patients died of recurrent disease.

\section{Survival analyses}

Of the patients with successful ablation, $87 \%$ (S.E. $4.8 \%$ ) were still free of the disease 10 years later. Of the patients with unsuccessful ablation who eventually did become free of disease, only 50\% (S.E. 14\%) were still free of the disease after 10 years (Fig. 2). The difference between the two Kaplan-Meier curves was significant $(\log$ rank $=11.1, P<0.001)$. At 5 years, diseasefree survival was $93 \%$ versus $62 \%$.

In patients who were alive at the 1-year follow-up, those with successful ablation had a thyroid-cancerspecific survival of $100 \%$ for the 5 years after ablation and $95 \%$ (S.E. $4.1 \%$ ) for the 10 years after ablation, whereas patients with unsuccessful ablation had a thyroid cancer-specific survival of $89 \%$ (s.E. $4.0 \%$ ) for the 5 years after ablation and $78 \%$ (s.E. 8.3\%) for the 10 years after ablation (Fig. 3). The difference between these two survival curves was also statistically significant $(\log$ rank $=7.16 ; P=0.007)$.

We analysed factors at the time of ablation that might influence the outcome of the first dosage of I-131. Results of these analyses are displayed in Table 2. Patients with a higher serum Tg level at the time of ablation $(P<0.001)$, patients with lymphnode metastasis discovered pre- or perioperatively $(P=0.04)$ and patients with distant metastasis $(P<0.001)$ turned out to have less chance of achieving successful ablation with the initial dosage of I-131.

\section{Discussion}

Our study shows that the success of ablation is a prognostic factor for disease-free interval and survival in

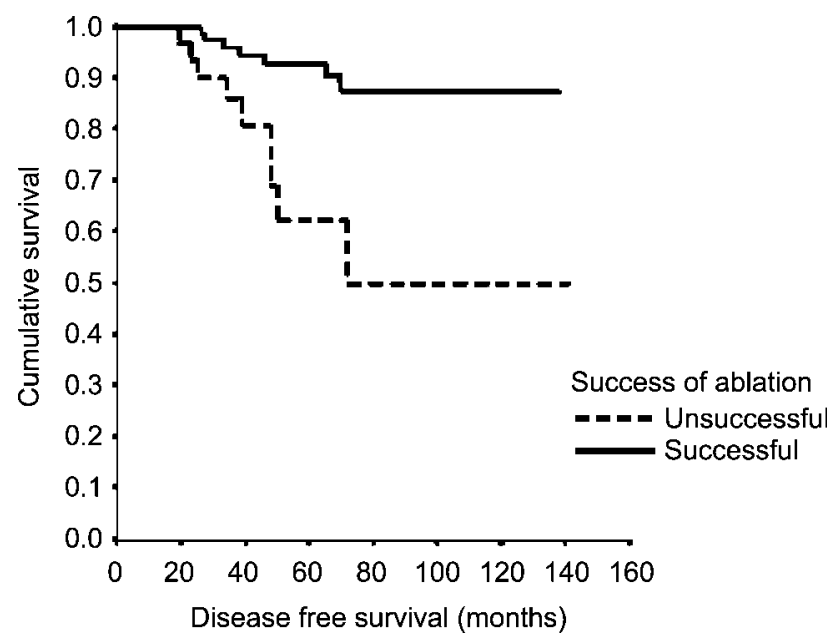

Figure 2 Kaplan-Meier plot of the duration of the disease-free interval in patients with successful and those with unsuccessful ablation.

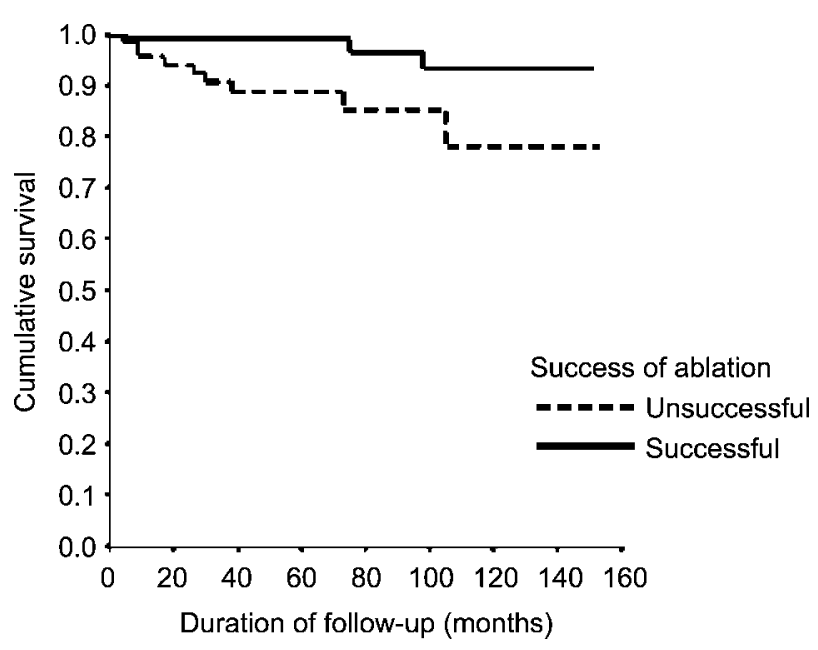

Figure 3 Kaplan-Meier plot of the thyroid-cancer-specific survival in patients with successful and those with unsuccessful ablation.

differentiated thyroid cancer patients. Unsuccessful ablation carries with it a considerably higher risk of recurrence; more importantly, it is not even certain that a patient can be made free of detectable disease. Our results support previous studies on the beneficial effects of radioiodine ablation for prognosis of patients with differentiated thyroid cancer $(2,5,20)$. In these studies, however, success of ablation as determined by $\mathrm{Tg}$ levels and scintigraphy was not reported as a prognostic factor. Some factors can influence the success of ablation. These factors include $\mathrm{Tg}$ levels at time of ablation, presence of pathological lymph nodes and distant metastasis. Since Tg is produced by normal or neoplastic thyrocytes, one can assume that higher $\mathrm{Tg}$ levels indicate a larger mass of functioning thyroid cells. Therefore, the chance of successful ablation is determined by the mass of normal and neoplastic thyroid tissue remaining after surgery. What could be of further importance is the grade of differentiation of the thyroid cancer cells. In some patients, the carcinoma de-differentiates in the course of the disease $(21,22)$. One of the mechanisms affected by this de-differentiation is the sodium-iodine symporter, which is essential for the uptake of I-131 by thyroid cancer cells. Cells that do not take up I-131 are much more likely to be persistent, but cannot be seen or measured scintigraphically. It is

Table $2 P$ values of factors influencing success of ablation.

\begin{tabular}{lr}
\hline Possible prognostic variable & $\boldsymbol{P}$ \\
\hline Age & 0.09 \\
TSH levels & 0.19 \\
Total thyroxine levels & 0.17 \\
Tg levels & $<0.001$ \\
Sex & 0.07 \\
Papillary/follicular carcinoma & 1.00 \\
Tumour diameter & 0.15 \\
Nodular metastasis & 0.04 \\
Distant metastasis & $<0.001$ \\
\hline
\end{tabular}


therefore impossible to say how much our results are influenced by this phenomenon.

Finding that a patient has an unsuccessful ablation adversely affects prognosis: a considerable number of patients in whom initial ablation was unsuccessful will never, or only after a number of additional therapeutic dosages of I-131, become free of detectable disease. Furthermore, even if they eventually do become free of disease, there is an increased chance that the thyroid cancer will return sooner or later.

Lymph-node or distant metastasis is a well-known adverse prognostic variable for thyroid cancer $(2,3$, 23-26). Surprising, however, the age at the time of ablation had no statistically significant influence on the outcome of the first dosage of I-131 in our study population. Normally, age is considered to be one of the more important prognostic factors in thyroid cancer.

Several studies have reported that high Tg levels at the time of ablation can be related to initial metastasis or recurrence (27-32). Muratet et al. (13) also found a significant relationship between $\mathrm{Tg}$ levels and the chance of successful ablation. Interestingly, they observed that a rise in $\mathrm{Tg}$ levels shortly after administration of I-131 is correlated with a lower chance of successful ablation. A similar report came from the group of Baudin et al. (32), who reported that the slope of rise or fall of Tg levels measured in high TSH conditions, compared with Tg levels at the time of ablation, had the higher value for prediction of recurrences.

Further research into the significance of $\mathrm{Tg}$ levels at the time of ablation seems warranted, especially with regard to the success of ablation. This could possibly lead to improved dosage schemes for individual patients. In that area, it would be interesting to conduct further research into the significance of measuring $\mathrm{Tg}$ levels after the ablative dosage: what is the earliest moment that they need to be undetectable during TSH stimulation, if there is to be a chance of achieving complete ablation? This could possibly lead to earlier additional therapy. In order to answer this question, we may want to turn to I-131 therapy for benign conditions. In patients treated for benign thyroid diseases, no further effect of I-131 therapy can be measured from 3 months after administration onward (33-35). This is considered to be so, even though 3 months after ablation would be much earlier than recent recommendations of 6-12 months (36). Perhaps that would be a good point in time for post-ablation follow-up, instead of the current follow-up at 1 year. This means that any thyroid cancer cell not killed in the first blast will have 9 months less to proliferate and spread.

Unsuccessful ablation is an adverse event in the follow-up of differentiated thyroid carcinoma. Patients in whom this is found should be followed much more intensively than patients in whom ablation was successful: they may never become free of disease, and even if they do, there is a high risk of recurrence.
Therefore, it seems important to treat thyroid cancer as early and as intensively as possible, in order to achieve the best possible prognosis for patients.

In conclusion, unsuccessful ablation dramatically lowers the prognosis of disease-free survival in patients; they should be followed much more intensively than those in whom ablation was successful with one dosage. The extent of the remaining normal or neoplastic thyroid tissue contributes to a higher risk of unsuccessful ablation after the first dosage of I-131 for the treatment of thyroid cancer.

\section{References}

1 Schlumberger MJ. Papillary and follicular thyroid carcinoma. New England Journal of Medicine 1998338 297-306.

2 Mazzaferri EL \& Jhiang SM. Long-term impact of initial surgical and medical therapy on papillary and follicular thyroid cancer. American Journal of Medicine 1994 97 418-428.

3 Simpson WJ, McKinney SE, Carruthers JS, Gospodarowicz MK, Sutcliffe SB \& Panzarella T. Papillary and follicular thyroid cancer. Prognostic factors in 1,578 patients. American Journal of Medicine 198783 479-488.

4 DeGroot LJ, Kaplan EL, McCormick M \& Straus FH. Natural history, treatment, and course of papillary thyroid carcinoma. Journal of Clinical Endocrinology and Metabolism $1990 \quad 71$ 414-424.

5 Samaan NA, Schultz PN, Hickey RC, Goepfert H, Haynie TP, Johnston DA \& Ordonez NG. The results of various modalities of treatment of well differentiated thyroid carcinomas: a retrospective review of 1599 patients. Journal of Clinical Endocrinology and Metabolism $199275714-720$.

6 Sawka AM, Thephamongkhol K, Brouwers M, Thabane L, Browman G \& Gerstein HC. Clinical review 170: a systematic review and metaanalysis of the effectiveness of radioactive iodine remnant ablation for well-differentiated thyroid cancer. Journal of Clinical Endocrinology and Metabolism $2004 \mathbf{8 9}$ 3668-3676.

7 Doi SA \& Woodhouse NJ. Ablation of the thyroid remnant and ${ }^{131}$ I dose in differentiated thyroid cancer. Clinical Endocrinology (Oxford) 200052 765-773.

8 de Klerk JM, de Keizer B, Zelissen PM, Lips CM \& Koppeschaar HP. Fixed dosage of ${ }^{131} \mathrm{I}$ for remnant ablation in patients with differentiated thyroid carcinoma without pre-ablative diagnostic ${ }^{131} \mathrm{I}$ scintigraphy. Nuclear Medicine Communications 200021 529-532.

9 Arslan N, Ilgan S, Serdengecti M, Ozguven MA, Bayhan H, Okuyucu K \& Gulec SA. Post-surgical ablation of thyroid remnants with high-dose (131)I in patients with differentiated thyroid carcinoma. Nuclear Medicine Communications 200122 1021-1027.

10 Cailleux AF, Baudin E, Travagli JP, Ricard M \& Schlumberger M. Is diagnostic iodine-131 scanning useful after total thyroid ablation for differentiated thyroid cancer? Journal of Clinical Endocrinology and Metabolism $2000 \mathbf{8 5} 175-178$.

11 Logue JP, Tsang RW, Brierley JD \& Simpson WJ. Radioiodine ablation of residual tissue in thyroid cancer: relationship between administered activity, neck uptake and outcome. British Journal of Radiology 199467 1127-1131.

12 Leung SF, Law MW \& Ho SK. Efficacy of low-dose iodine-131 ablation of post-operative thyroid remnants: a study of 69 cases. British Journal of Radiology 199265 905-909.

13 Muratet JP, Giraud P, Daver A, Minier JF, Gamelin E \& Larra F. Predicting the efficacy of first iodine-131 treatment in differentiated thyroid carcinoma. Journal of Nuclear Medicine $1997 \mathbf{3 8}$ 1362-1368.

14 Goslings BM. Proceedings: effect of a low iodine diet on 131-I therapy in follicular thyroid carcinomata. Journal of Endocrinology $19756430 \mathrm{P}$. 
15 Park HM, Perkins OW, Edmondson JW, Schnute RB \& Manatunga A. Influence of diagnostic radioiodines on the uptake of ablative dose of iodine-131. Thyroid 19944 49-54.

16 Muratet JP, Daver A, Minier JF \& Larra F. Influence of scanning doses of iodine-131 on subsequent first ablative treatment outcome in patients operated on for differentiated thyroid carcinoma. Journal of Nuclear Medicine 199839 1546-1550.

17 Leger FA, Izembart M, Dagousset F, Barritault L, Baillet G, Chevalier A \& Clerc J. Decreased uptake of therapeutic doses of iodine-131 after $185-\mathrm{MBq}$ iodine-131 diagnostic imaging for thyroid remnants in differentiated thyroid carcinoma. European Journal of Nuclear Medicine 199825 242-246.

18 Spencer CA, Takeuchi M, Kazarosyan M, Wang CC, Guttler RB, Singer PA, Fatemi S, LoPresti JS \& Nicoloff JT. Serum thyroglobulin autoantibodies: prevalence, influence on serum thyroglobulin measurement, and prognostic significance in patients with differentiated thyroid carcinoma. Journal of Clinical Endocrinology and Metabolism $1998 \mathbf{8 3} 1121-1127$.

19 Mariotti S, Barbesino G, Caturegli P, Marino M, Manetti L, Pacini F, Centoni R \& Pinchera A. Assay of thyroglobulin in serum with thyroglobulin autoantibodies: an unobtainable goal? Journal of Clinical Endocrinology and Metabolism $1995 \mathbf{8 0} 468-472$.

20 Simpson WJ, Panzarella T, Carruthers JS, Gospodarowicz MK \& Sutcliffe SB. Papillary and follicular thyroid cancer: impact of treatment in 1578 patients. International Journal of Radiation Oncology, Biology and Physics 198814 1063-1075.

21 Filetti S, Bidart JM, Arturi F, Caillou B, Russo D \& Schlumberger M. Sodium/iodide symporter: a key transport system in thyroid cancer cell metabolism. European Journal of Endocrinology 1999 $141443-457$.

22 Goretzki PE, Simon D, Frilling A, Witte J, Reiners C, Grussendorf M, Horster FA \& Roher HD. Surgical reintervention for differentiated thyroid cancer. British Journal of Surgery $1993 \mathbf{8 0}$ 1009-1012.

23 Cady B \& Rossi R. An expanded view of risk-group definition in differentiated thyroid carcinoma. Surgery $1988 \mathbf{1 0 4}$ 947-953.

24 Sherman SI, Brierley JD, Sperling M, Ain KB, Bigos ST, Cooper DS, Haugen BR, Ho M, Klein I, Ladenson PW, Robbins J, Ross DS, Specker B, Taylor T \& Maxon HR 3rd. Prospective multicenter study of thyroid carcinoma treatment: initial analysis of staging and outcome. National Thyroid Cancer Treatment Cooperative Study Registry Group. Cancer 199883 1012-1021.

25 Loh KC, Greenspan FS, Gee L, Miller TR \& Yeo PP. Pathological tumor-node-metastasis (pTNM) staging for papillary and follicular thyroid carcinomas: a retrospective analysis of 700 patients. Journal of Clinical Endocrinology and Metabolism $1997 \mathbf{8 2}$ 3553-3562.

26 Pacini F, Cetani F, Miccoli P, Mancusi F, Ceccarelli C, Lippi F, Martino E \& Pinchera A. Outcome of 309 patients with metastatic differentiated thyroid carcinoma treated with radioiodine. World Journal of Surgery 199418 600-604.

27 Grunwald F, Menzel C, Fimmers R, Zamora PO \& Biersack HJ. Prognostic value of thyroglobulin after thyroidectomy before ablative radioiodine therapy in thyroid cancer. Journal of Nuclear Medicine 199637 1962-1964.

28 Ronga G, Filesi M, Ventroni G, Vestri AR \& Signore A. Value of the first serum thyroglobulin level after total thyroidectomy for the diagnosis of metastases from differentiated thyroid carcinoma. European Journal of Nuclear Medicine 199926 1448-1452.

29 Hall FT, Beasley NJ, Eski SJ, Witterick IJ, Walfish PG \& Freeman JL. Predictive value of serum thyroglobulin after surgery for thyroid carcinoma. Laryngoscope 2003113 77-81.

30 Tenenbaum F, Corone C, Schlumberger M \& Parmentier C. Thyroglobulin measurement and postablative iodine-131 total body scan after total thyroidectomy for differentiated thyroid carcinoma in patients with no evidence of disease. European Journal of Cancer 1996 32A 1262.

31 Ruiz-Garcia J, Ruiz de Almodovar JM, Olea N \& Pedraza V. Thyroglobulin level as a predictive factor of tumoral recurrence in differentiated thyroid cancer. Journal of Nuclear Medicine 1991 32 395-398.

32 Toubeau M, Touzery C, Arveux P, Chaplain G, Vaillant G, Berriolo A, Riedinger JM, Boichot C, Cochet A \& Brunotte F. Predictive value for disease progression of serum thyroglobulin levels measured in the postoperative period and after (131)I ablation therapy in patients with differentiated thyroid cancer. Journal of Nuclear Medicine $200445988-994$.

33 Baudin E, Do Cao C, Cailleux AF, Leboulleux S, Travagli J \& Schlumberger M. Positive predictive value of serum thyroglobulin levels, measured during the first year of follow-up after thyroid hormone withdrawal, in thyroid cancer patients. Journal of Clinical Endocrinology and Metabolism $2003 \mathbf{8 8} 1107-1111$.

34 Stensvold AD, Jorde R \& Sundsfjord J. Late and transient increases in free T4 after radioiodine treatment for Graves' disease. Journal of Endocrinological Investigation 199720 580-584.

35 Benua RS \& Dobyns BM. Iodinated compounds in the serum, disappearance of radioactive iodine from the thyroid, and clinical response in patients treated with radioactive iodine. Journal of Clinical Endocrinology and Metabolism 195515 118-130.

36 Schlumberger M, Berg G, Cohen O, Duntas L, Jamar F, Jarzab B, Limbert E, Lind P, Pacini F, Reiners C, Sanchez Franco F, Toft A \& Wiersinga WM. Follow-up of low-risk patients with differentiated thyroid carcinoma: a European perspective. European Journal of Nuclear Medicine 2004150 105-112.

Received 21 July 2004

Accepted 5 October 2004 